\title{
Pengaruh Kedisiplinan Terhadap Kinerja Karyawan Pada PT Telkomsel Area IV Pamasuka Kota Makassar
}

\author{
Aprizal $^{1}$, Kurniaty $^{2}$, Hasriani $^{1 *}$ \\ ${ }^{1}$ STMIK Dipanegara, Makassar, Indonesia \\ ${ }^{2}$ Sekolah Pascasarjana Universitas Hasanuddin, Indonesia \\ E-mail: hasriani@dipanegara.ac.id
}

\begin{abstract}
Abstrak
Penelitian ini adalah untuk mengetahui apakah kedisiplinan berpengaruh secarah signifikan terhadap kinerja dan seberapa besar pengaruh kesiplinan terhadap kinerja karyawan pada PT Telkomsel Area IV Pamasuka Makassar. Penelitian ini termasuk jenis penelitian kuantitatif dengan pengujian hipotesis. Populasi dalam penelitian ini sebanyak 60 responden dan semua populasi dijadikan sebagai sampel sebanyak 60 sapel. Teknik pengumpulan data dalam penelitian ini menggunakan kuesioner, dan observasi. Sedangkan teknik analisis data yang digunakan adalah analisis regresi sederhana dengan rumus $\mathrm{Y}=\mathrm{a}+\mathrm{bx}$. Hasil analisis dan pembahasan diperoleh nilai signifikan untuk variabel $\mathrm{X}$ sebesar $0,000<0,05$ maka Ho ditolak dan Ha diterima, artinya ada pengaruh signifikan kedisiplinan terhadap kinerja, pada PT Telkomsel Area IV Pamasuka Makassar dan juga dapat diperoleh besar nilai pengaruhnya kedisplina terhadap kinerja sebesar 0,485 atau 48,5\%. Hal ini menjelaskan tujuan dari penelitian ini, serta model regresi $\mathrm{Y}=1,068+0,723 \mathrm{X}$.
\end{abstract}

Kata Kunci: kedisiplinan dan kinerja.

\begin{abstract}
This research is to find out whether discipline has a significant effect on performance and how much the influence of discipline on employee performance at PT Telkomsel Area IV Pamasuka Makassar. This research is quantitative research with hypothesis testing. The population in this study were 60 respondents and all populations were sampled as many as 60 saples. Data collection techniques in this study used a questionnaire, and observation. While the data analysis technique used is a simple regression analysis with the formula $Y=a+b x$. The results of the analysis and discussion obtained a significant value for variable $X$ of $0,000<0.05$ then Ho is rejected and Ha is accepted, meaning that there is a significant influence of discipline on performance, at PT Telkomsel Area IV Pamasuka Makassar and it can also be obtained the value of the influence of discipline on performance by 0.485 or $48.5 \%$. This explains the purpose of this study, as well as the regression model $Y=$ $1.068+0.723 X$.
\end{abstract}

Keywords: discipline and performance.

\section{Pendahuluan}

Sumber Daya Manusia (SDM) adalah salah satu faktor yang sangat berperan penting bahkan tidak dapat dilepaskan dari sebuah organisasi, institusi, maupun suatu perusahaan. Sumber daya manusia juga merupakan kunci keberhasilan atau yang menentukan perkembangan dan kemajuan suatu organisasi, institusi, maupun perusahaan. Pada hakikatnya SDM berupa manusia yang dipekerjakan di sebuah organisasi sebagai penggerak dalam mengikuti aturan-aturan, pemikir, dan perencana untuk mencapai suatu tujuan dari organisasi, instansi, maupun suatu perusahaan.

Hal ini sejalan dengan maksud dari pada penelitian yang diungkapkan oleh (Farid and Hamid 2016), yang menjelaskan bahwa terdapat hubungan antara disiplin kerja bagian dari pada SDM terhadap peningkatan kinerja. Oleh karena itu, manusia dituntut memberikan prestasi terhadap organisasi kelembagaan, baik dalam lingkungan kerja maupun dalam lingkungan keluarga. Manusia pada umumnya manusia memiliki kapasitas dan potensi (Khasinah 2013 \& Zalik Nuryana 2017), sehingga mendukung dirinya untuk memberikan keahlian atau skill. Manusia tentunya tidak bisa keluar dari koridor dan tanggung jawab untuk memakmurkan bumi ini (Daud 2008).

\footnotetext{
* Corresponding author
}

Untuk itulah manusia harus memenuhi tugas dan kewajiban dalam memenuhi tanggung jawab yang diberikan kepadanya. Dengan sumber daya yang dimiliki tersebut, manusia dapat memenuhi kebutuhan sebagai balas jasa atas pekerjaan yang dimiliknya (Habibi 2014). Balas jasa tersebut bisa didapatkan dari lembaga (Lingkungan Kerja) maupun didapat dari keluarga, sehingga terjadi kesetaraan antara potensi (Sumber Daya) dengan kemampuan (skill) yang dimiliki manusia.

Sumber Daya Manusia (SDM) sangat dibutuhkan dalam suatu lembaga, dapat meningkatkan kualitas kerja dan produktivitas kerja serta kedisplinan (Setiawan 2017), sehingga memberi timbal balik yang baik serta kepuasaan terhadap karyawan dan lembaga tercipta. Organisasi atau lembaga harus memiliki nilai (keunggulan) lebih dibandingkan dengan organisasi lain. Tetapi organisasi atau lembaga tidak bisa berdiri tanpa ada sumber daya yang mendukung diantaranya kedisiplinan, karena ini sangat berpengaruh dalam kamajuan suatu lembaga (Setiawan 2017).

Agar dapat menjadi sumber keunggulan bersaing melalui peningkatan modal manusia diantaranya kedisiplinan dalam bekerja, lembaga memerlukan suatu aturan tegas untuk dapat bersaing dan beradaptasi dengan lembaga lainya (Suhartono 2016). Dewasa ini perubahan lingkungan bisnis yang sangat cepat menuntut peran sumber daya manusia dalam 
keunggulan barsaing (Wayan 2007). Hal ini berarti bahwa organisasi harus dapat meningkatkan hasil kerja yang diraih sekarang untuk memperoleh hasil kerja yang lebih baik dimasa depan.

Kedisiplinan merupakan subfungsi Manajemen Sumber Daya Manusia (MSDM) yang terpenting dan kunci terwujudnya tujuan, karena tanpa disiplin yang baik sulit terwujud tujuan yang maksimal (Hasibuan 2016). Untuk itulah kedisiplinan ini sangat dibutuhkan demi terwujudnya misi suatu lembaga. Subfungsi utama dari sumber daya manusia menurut Hasibuan adalah kedisiplinan. Untuk itulah kedisiplinan ini sangat dibutuhan demi terwujudnya misi suatu lembaga. Dari pendapat ini dapat dilihat bahwa kedisiplinan itu sangat penting, sikap menghormati, menghargai, patuh dan taat itu merupakan suatu kedisiplinan yang wajib dimiliki oleh karyawan.

Disiplin karyawan itu sangat dibutuhkan dalam suatu lembaga atau perusahaan, menjalankan segala aturan yang ditetapkan dengan tingkah laku, sikap yang baik serta menyikapi aturan tersebut dengan baik tanpa ada intervensi dari pihak lain hal ini dituturkan oleh Hodges dalam (Helmi 1996). Disiplin karyawan merupakan perilaku seseorang dengan peraturan prosedur kerja yang ada atau disiplin adalah sikap, tingkah laku, dan perbuatan sesuai dengan peraturan dari organisasi baik itu tertulis maupun yang tidak tertulis (Helmi 1996).

Demikian halnya dengan PT Telkomsel Area IV Pamasuka Makassar sebagai salah satu perusahaan yang bergerak di bidang operator jasa telekomonikasi seluler dengan frekuensi jaringan operator 900/1800 GSM, yang berdiri pada tanggal 26 Mei tahun 1995. Karyawan saat ini sudah melalui proses seleksi dan telah mempunyai berbagai kemampuan tambahan yang didapat dari training baik didalam maupun diluar perusahaan, akan tetapi training saja tidaklah cukup, perlu adanya peningkatan soft skill yang harus dimiliki oleh karyawan itu sendiri, misalnya kemampuan untuk berkomonikasi, berkerja sama, jujur, ulet dan percaya diri dalam menyelesaikan suatu pekerjaan dengan disertai oleh sikap disiplin kerja sehingga kinerja karyawan diperusahaan dapat tercapai secara optimal.

Telkomsel memiliki kode etik perusahaan (Code Of Conduct) yang merupakan turunan dan implementasi dari budaya perusahaan The Telkomsel Way. Setiap karyawan PT Telkomsel Area IV Pamasuka Makassar, wajib untuk menerima dan menerapkan budaya perusahaan dan kode etik perusahaan sebagai panduan bertindak dalam menetapkan hubungan kerja pola pikir, sikap dan perilaku sehari-hari dengan sesama karyawan dan atau pihak-pihak lainya yang meliputi namun tidak terbatas pada mitra kerja perusahaan, pemerintah, masyarakat, media massa.

Seperti yang diatur dalam kode etik perusahaan, karyawan diminta untuk berperilaku sesuai dengan nilai-nilai (The Telkomsel Way Is Integriti, Respect, Enthusiasm, Loyality And Totality). Dengan adanya hal tersebut seluruh karyawan yang ada di PT Telkomsel Area IV Pamasuka Makassar dituntut untuk memperhatikan waktu kerja. Menurut dari laman CNN Indonesia tahun 2015 menyatakan bahwa dengan keberhasilan yang didapatkan selama tiga tahun terakhir terkait di dalam kinerja yang positif maka diharapkan pihak manajemen mempertahankan kinerja positifnya.
Adapun masalah-masalah yang menyangkut disiplin dan kinerja saat ini yang ada pada PT Telkomsel Area IV Pamasuka Makassar yang perlu mendapat perhatian adalah mengenai disiplin karyawan dalam ketepatan waktu kerja karena lemahnya pengawasan terhadap ketepatan waktu kerja terhadap karyawan. Untuk pekerjaan yang mengacu terhadap prosedur dan petunjuk kerja masih saja ada yang dikerjakan sekehendak hati tanpa memperhatikan aspek-aspek teknis dalam prosedur dan petunjuk kerja.

Hal lainya mengenai pelaksanaan pekerjaan yang tidak sesuai dengan target yang diberikan oleh perusahaan, sehingga sering terlambat memberikan informasi terhadap setiap mitramitra yang ada. Contohnya adalah ketika bagian vendor manajemen terlambat memberikan informasi terhadap setiap mitra yang belum melengakapi data-data perusahaannya di Aplikasi Verona. Memang tidak semua karyawan melakukan hal-hal yang bersifat melanggar terhadap peraturan perusahaan, ada juga karyawan yang selalu disiplin dalam melaksanakan tugas yang diberikan kepadanya.

\section{Metode}

\section{Metode Pengumpulan Data}

\section{Kuesioner}

Kuesioner adalah sejumlah pertanyaan atau pernyataan tertulis tentang data faktual atau opini yang berkaitan dengan diri responden, yang dianggap fakta atau kebenaran yang diketahui dan perlu dijawab oleh responden.

\section{Observasi}

Observasi merupakan pengamatan langsung terhadap suatu objek yang ada di lingkungan yang sedang berlangsung meliputi berbagai aktivitas perhatian terhadap kajian objek dengan menggunakan pengindraan (Arikunto 2017).

\section{Jenis Data dan Sumber data}

\section{Jenis data \\ a. Data Primer}

Data primer adalah data yang diperoleh langsung dari sumbernya, diamati dan dicatat untuk yang pertama kalinya. Data dalam penelitian diperoleh dari karyawan PT Telkomsel Area IV Pamasuka Makassar untuk dijawab dengan sejujurnya serta melakukan observasi kelapangan dimana laokasi kantor berada.

\section{b. Data Sekunder}

Data sekunder adalah data yang bukan di usahakan sendiri. Data ini diperoleh dari buku-buku dan jurnal yang menyangkut tentang penelitian tersebut.

\section{Sumber Data}

Sumber data dalam penelitian ini adalah internal data yang diperoleh dari lokasi penelitian. Agar kegiatan penelitian ini dapat terlaksana dengan baik dan sesuai dengan yang diharapkan peneliti, maka diperlukan data yang bersifat obyektif dan relevan dengan judul yang diajukan peneliti karena data ini sangat penting. Sumber data yang diperoleh peneliti dari PT Telkomsel Area IV Pamasuka Makassar.

\section{Populasi dan Sampel}

\section{Populasi}

Populasi adalah jumlah keseluruhan dari objek yang diteliti. Populasi yang dijadikan objek penelitian ini adalah seluruh 
karyawan yang ada di lantai 4 PT Telkomsel Area IV Pamasuka Makassar, yang berjumlah 60 responden.

\section{Sampel}

Sampel adalah sebagian dari populasi yang dijadikan objek penelitian. Menurut (Arikunto 2003), apabila populasi kurang dari 100, maka semuanya dijadikan sampel. Teknik pengambilan sampel dalam penelitian ini adalah sampel jenuh karena semua populasi dijadikan sampel. Jadi sampel yang diambil dalam penelitian ini adalah 60 responden.

\section{Metode Analisis}

Untuk menguji hipotesis, peneliti menggunakan analisis deskriptif dan analisis regresi sederhana. Analisis deskriptif digunakan untuk melihat dan menjelaskan tanggapan responden terhadap kedisiplinan dan peningkatan kinerja karyawan. Analisis regresi sederhana digunakan untuk mengetahui pengaruh kedisiplinan terhadap kinerja karyawan, dalam hal ini peneliti menggunakan bantuan pengolah data SPSS 20.

Berikut ini rumus dari analisis regresi sederhana:

$\mathrm{Y}=\mathrm{a}+\mathrm{bX}$

Keterangan:

$\mathrm{Y}=$ Kinerja

$\mathrm{X}=$ Kedisiplinan

$\mathrm{a}=$ Nilai konstanta

$\mathrm{b}=$ Koefisien regresi

Pengelolaan data kuesioner menggunakan skala likert (Sugiyono 2003), skala likert digunakan untuk mengukur sikap, pendapat, dan presepsi seseorang atau kelompok orang tentang fenomena sosial. Skala likert mempunyai interval $1-$ 5. Untuk jawaban yang yang mendukung diberi skor tertinggi dan untuk jawaban yang tidak mendukung pernyataan diberi skor terendah misalnya sebagai berikut :

- Sangat setuju (SS) diberi skor $\quad=5$

- Setuju (S) diberi skor

$=4$

- Kurang setuju (KS) diberi skor

$=3$

- Tidak setuju (TS) diberi skor

$=2$

- Sangat tidak setuju (STS) diberi skor

$$
=1 \text {. }
$$

\section{Hasil dan Pembahasan}

\section{Uji Asumsi Klasik}

Untuk mengetahui apakah model regresi linear dapat digunakana atau tidak, maka terlebih dahulu dilakukan uji asumsi klasik yaitu:

\section{Uji Validitas}

Uji Validitas variabel Independen (X) Kedisiplinan

Tabel 1. Validitas Kedisiplinan

\begin{tabular}{|c|c|c|c|c|}
\hline Item & Signifikasi & $\begin{array}{c}\text { Tingkat } \\
\text { Correlation } \\
\text { Person }\end{array}$ & $\begin{array}{c}\text { Tingkat } \\
\text { Validitas }\end{array}$ & Kategori \\
\hline X1.1 & 0,000 & $76,5 \%$ & $<0,05$ & Valid \\
\hline X1.2 & 0,000 & $62,1 \%$ & $<0,05$ & Valid \\
\hline X1.3 & 0,001 & $43,6 \%$ & $<0,05$ & Valid \\
\hline X1.4 & 0,000 & $62,5 \%$ & $<0,05$ & Valid \\
\hline X1.5 & 0,000 & $76,5 \%$ & $<0,05$ & Valid \\
\hline X1.6 & 0,000 & $55,9 \%$ & $<0,05$ & Valid \\
\hline X1.7 & 0,001 & $43,0 \%$ & $<0,05$ & Valid \\
\hline X1.8 & 0,000 & $51,6 \%$ & $<0,05$ & Valid \\
\hline
\end{tabular}

Uji validitas variable dependen (Y) kinerja

Tabel 2. Validitas Kinerja

\begin{tabular}{|c|c|c|c|c|}
\hline Item & Signifikasi & $\begin{array}{c}\text { Tingkat } \\
\text { Correlation } \\
\text { Person }\end{array}$ & $\begin{array}{c}\text { Tingkat } \\
\text { Validitas }\end{array}$ & Kategori \\
\hline Y1.1 & 0,000 & $56,7 \%$ & $<0,05$ & Valid \\
\hline Y1.2 & 0,000 & $63,8 \%$ & $<0,05$ & Valid \\
\hline Y1.3 & 0,000 & $57,6 \%$ & $<0,05$ & Valid \\
\hline Y1.4 & 0,000 & $72,6 \%$ & $<0,05$ & Valid \\
\hline Y1.5 & 0,000 & $59,0 \%$ & $<0,05$ & Valid \\
\hline Y1.6 & 0,000 & $52,3 \%$ & $<0,05$ & Valid \\
\hline Y1.7 & 0,000 & $63,8 \%$ & $<0,05$ & Valid \\
\hline Y1.8 & 0,000 & $53,8 \%$ & $<0,05$ & Valid \\
\hline
\end{tabular}

Uji Reliabilitas

Tabel 3. Reliabiliti

Reliability Statistics

\begin{tabular}{|c|c|}
\hline $\begin{array}{c}\text { Cronbach's } \\
\text { Alpha }\end{array}$ & N of Items \\
\hline .799 & 9 \\
\hline
\end{tabular}

Uji Normalitas

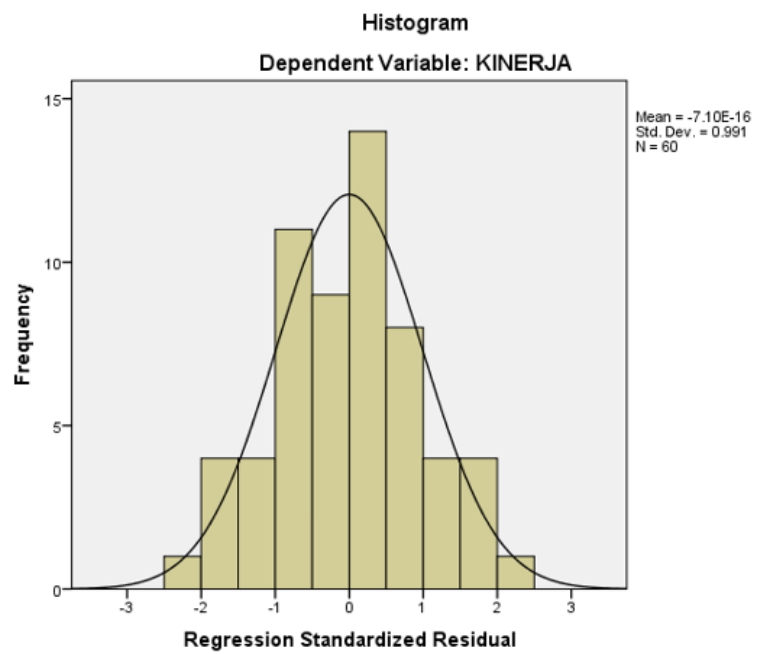

Gambar 1 Histogram Dependen

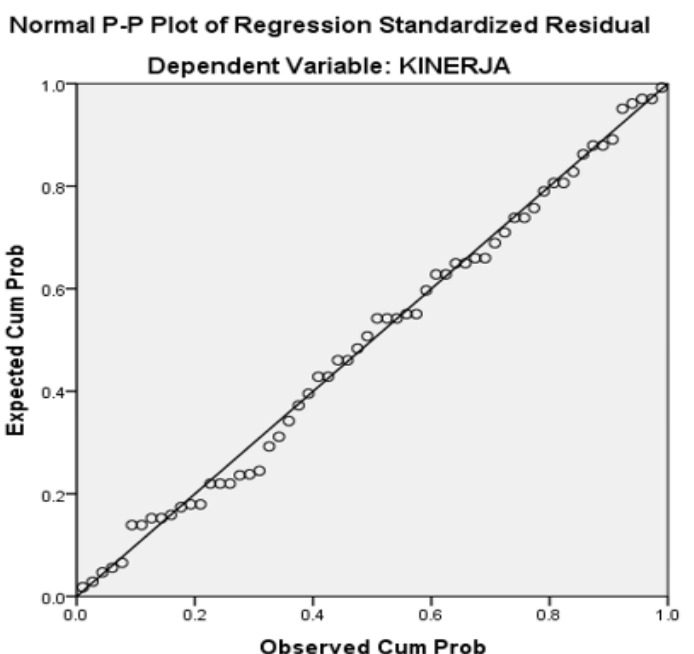

Gambar 2 P-P plot 
Tabel 4. Normalitas

One-Sample Kolmogorov-Smirnov Test

\begin{tabular}{|ll|r|}
\hline & & $\begin{array}{c}\text { Unstandardized } \\
\text { Residual }\end{array}$ \\
\hline N & Mean & 60 \\
Normal Parameters & $0 \mathrm{E}-7$ \\
& Std. Deviation & .30290474 \\
& Absolute & .074 \\
Most Extreme Differences & Positive & .074 \\
& Negative & -.054 \\
Kolmogorov-Smirnov Z & & .571 \\
Asymp. Sig. (2-tailed) & & .900 \\
\hline
\end{tabular}

a. Test distribution is Normal.

b. Calculated from data.

\section{Uji Heteroskedastisitas}

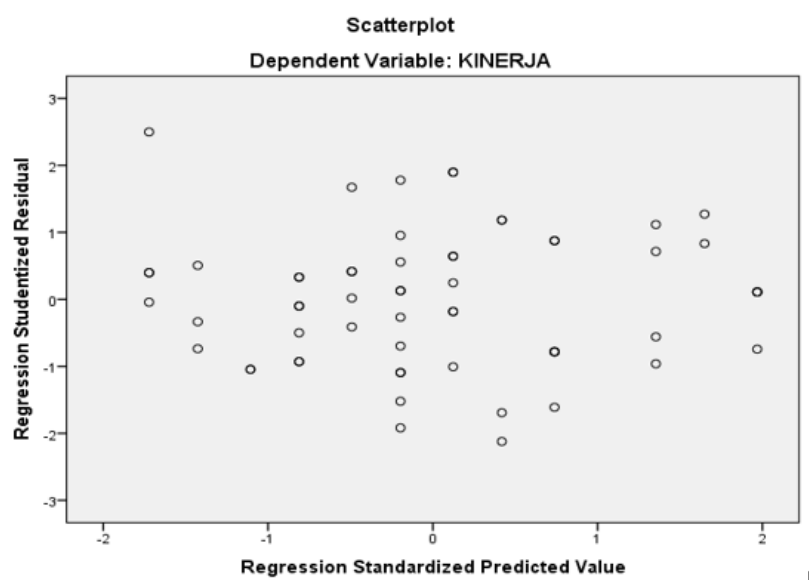

Gambar 3. Heteroskedastisitas

\section{Uji Regresi Sederhana}

Tabel 5. Uji Koefisien Determinasi

\begin{tabular}{|l|c|c|c|c|}
\hline Model & $\mathrm{R}$ & \multicolumn{1}{|c|}{ R Square } & Adjusted R Square & $\begin{array}{c}\text { Std. Error of the } \\
\text { Estimate }\end{array}$ \\
\hline 1 & $.697^{\mathrm{a}}$ & .485 & .476 & .30550 \\
\hline
\end{tabular}

a. Predictors: (Constant), KEDISIPLINAN

b. Dependent Variable: KINERJA

Tabel 5 Hasil uji F secara simultan

\begin{tabular}{|c|c|c|c|c|c|c|}
\hline \multicolumn{7}{|c|}{ ANOVA $^{\mathrm{a}}$} \\
\hline Model & & Sum of Squares & df & Mean Square & $\mathrm{F}$ & Sig. \\
\hline \multirow{3}{*}{1} & Regression & 5.102 & 1 & 5.102 & 54.668 & $.000^{b}$ \\
\hline & Residual & 5.413 & 58 & .093 & & \\
\hline & Total & 10.516 & 59 & & & \\
\hline
\end{tabular}

a. Dependent Variable: KINERJA

b. Predictors: (Constant), KEDISIPLIAN

Tabel 6 Hasil uji T secara parsial

\begin{tabular}{|c|c|c|c|c|c|c|c|}
\hline \multicolumn{8}{|c|}{ Coefficients $^{\mathrm{a}}$} \\
\hline \multirow[t]{2}{*}{ Model } & \multicolumn{2}{|c|}{$\begin{array}{c}\text { Unstandardized } \\
\text { Coefficients }\end{array}$} & \multirow{2}{*}{$\begin{array}{c}\text { Standardized } \\
\text { Coefficients } \\
\text { Beta } \\
\end{array}$} & \multirow[t]{2}{*}{$t$} & \multirow[t]{2}{*}{ Sig. } & \multicolumn{2}{|c|}{ Collinearity Statistics } \\
\hline & B & Std. Error & & & & Tolerance & VIF \\
\hline (Constant) & 1.068 & .401 & & 2.661 & .010 & & \\
\hline KEDISIPLIAN & .723 & .098 & 697 & 7.394 & .000 & 1.000 & 1.000 \\
\hline
\end{tabular}

Hasil penelitian ini sekaligus juga menjawab pertanyaan yang keluar dari hipotesis penelitian antara lain sebagai berikut :
1. Diduga kedisplinan berpengaruh secara signifikan terhadap kinerja karyawan pada PT Telkomsel Area IV Pamasuka Makassar.

2. Berapa besar pengaruh kedisiplinan terhadap kinerja pada PT Telkomsel Area IV Pamasuka Makassar?

Berdasarkan analisa pembahasan yang telah diuraikan maka, dapat disimpulkan bahwa Ho ditolak dan Ha diterima dimana tingkat signifikan sebesar 0,000 $(<0,05)$ yang artinya adalah kedisiplinan berpengaruh secara positif dan signifikan terhadap kinerja karyawan telkomsel. Sedangkan tabel 4.15 uji koefisien determinasi menjelaskan bahwa dapat diperoleh nilai koefisien determinasi ( $\mathrm{R}$ square) sebesar 0,485 (nilai 0,485 adalah pengkuadratan dari koefisien korelasi atau $\mathrm{R}$ yaitu $0,485 \mathrm{x}$ 0,486=0,967). Angka tersebut mengandung arti bahwa kedisiplinan berpengaruh terhadap kinerja sebesar 48,5\%.

\section{Simpulan}

Penelitian yang dilakukan pada PT Telkomsel Area IV Pamasuka Makassar dengan judul pengaruh kedisplinan terhadap kinerja karyawan dan menggunakan teknik pengumpulan data berupa observasi dan kuisioner didapatkan model regresi $\mathrm{Y}=1,068+0,723 \mathrm{X}$ dengan menggunakan sampel sebanyak 60 responden dan dari hasil olah data dan pembahasan didapat nilai signifikan sebesar $0,000<0,05$ maka hipotesis yang diajukan diterima atau Ho di tolak dan Ha diterima artinya ada pengaruh signifikan antara kedisiplinan terhadap kinerja karyawan sedangkan besaran nilai pengaruh kedisiplinan terhadap kinerja sebesar 0,485 atau $48,5 \%$ nilai tersebut di dapat dari hasil olah data uji koefisien determinasi, hal ini menjelaskan tujuan dari penelitian ini.

\section{Ucapan Terima Kasih}

Tim penulis mengucapkan banyak terima kasih kepada pimpinan PT Telkomsel atas kesempatan yang diberikan peneliti dalam melakukan penelitian di kantor yang bapak pimpin, dan juga terima kasih kepada tim peneliti yaitu ibu Kurniaty dan ibu Hasriani atas kerjasamanya dalam menyelesaikan penelitian ini. Tak lupa juga kami ucapkan terima kasih kepada rekan kerja atas motivasi yang diberikan, dan seluruh pihak yang mendukung.

\section{Referensi}

Bangun, Wilson. 2013. Pengaruh Disiplin Terhadap Kinerja Karyawan. Universitas Winaya Mukti.

Daud, Waladan Mardiyya bin Daos bin. 2008. Tugas Manusia.

Habibi, Ahmad. 2014. Trade off Kerusakan Sumber Daya Alam Dan Pembangunan Ekonomi.

Hasibuan, Melayu S.P. 2016. Pengaruh Disiplin Terhadap Kinerja Karyawan. Universitas Winaya Mukti.

Bangun, Wilson. 2013. Pengaruh Disiplin Terhadap Kinerja Karyawan. Universitas Winaya Mukti.

Daud, Waladan Mardiyya bin Daos bin. 2008. Tugas Manusia.

Habibi, Ahmad. 2014. Trade off Kerusakan Sumber Daya Alam dan Pembangunan Ekonomi.

Hasibuan, Melayu S.P. 2013. Pengaruh Disiplin Terhadap Kinerja Karyawan. Universitas Winaya Mukti.

Malayu, S. P. 2017. Manajemen Sumber Daya Manusia.

Mangkunegara. 2017. Manajemen Sumber Daya Manusia. Bandung: PT. Remaja Rosdakarya.

Mathis, L. Robert, and H Jhon Jackson. 2006. Manajemen Sumber Daya Manusia. Human Reso. ed. Salemba Empat. Jakarta. 
Siagian.P.Sondang. 2018. Manajemen Sumber Daya Manusia. Bandung: Bumi Aksara.

Farid, Hendra Taufik, and Djamhur Hamid. 2016. "Pengaruh Motivasi Kerja Terhadap Kedisiplinan Dan Kinerja Pegawai Pt . Pln Distribusi Jawa Timur Area Malang." Jurnal Administrasi Bisnis (JAB) 32(1): 75-81.

Farid, Hendra Taufik, and Djamhur Hamid. 2016. "Pengaruh Motivasi Kerja Terhadap Kedisiplinan Dan Kinerja Pegawai Pt . Pln Distribusi Jawa Timur Area Malang." Jurnal Administrasi Bisnis (JAB) 32(1): 75-81.

Khasinah, Siti. 2013. "Hakikat Manusia Menurut Pandangan Islam Dan Barat.” Jurnal Ilmiah Didaktika XIII(2): 296-317.
Setiawan, Agung. 2017. "Pengaruh Disiplin Kerja Dan Motivasi Terhadap Kinerja Karyawan Pada Rumah Sakit Umum Daerah Kanjuruhan Malang Agung." Ilmu Manajemen 1(4): 1247.

Suhartono, Iman. 2016. "Strategi Pengembangan Koperasi Berorientasi Bisnis." Jurnal.Stiema.ac.id 4(7): 33-47.

Wayan, Mujiati Ni. 2007. "Pengelolaan SDM Untuk Menciptakan Keunggulan Kompetitif Ni Wayan Mujiati Fakultas Ekonomi Universitas Udayana.” Jurnal Universitas Udayana: 1-12.

Zalik Nuryana. 2017. "Kajian Potensi Manusia Sesuai Dengan Hakikatnya Dalam Pendidikan Holistik." (February): 32-38

Helmi, AF. 1996. "DISIPLIN KERJA Avin Fadilla Helmi." Buletin Psikologi (2): 32-42. 